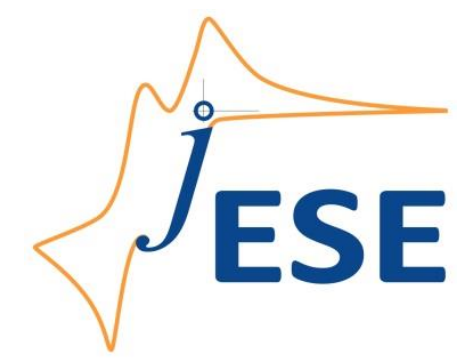

Open Access : : ISSN 1847-9286

www.jESE-online.org

Original scientific paper

\title{
Square wave and differential pulse voltammetric methods for the analysis of olivetol at gold electrode
}

\author{
Jyoti T. Bagalkoti, Vijay P. Pattar and Sharanappa T. Nandibewoor ${ }^{\bowtie}$ \\ P.G. Department of Studies in Chemistry, Karnatak University, Dharwad 580 003, India \\ ${ }^{\bowtie}$ Corresponding author: stnandibewoor@yahoo.com; Tel: +918362215286; Fax: +918362747884
}

Received: January 20, 2017; Revised: February16, 2017; Accepted: March 7, 2017

\begin{abstract}
Few electrochemical techniques have been employed for the determination of the powerful antitumor agent olivetol (OLV) in real samples at gold electrode. An intense and well pronounced oxidation peak was obtained at $1.04 \mathrm{~V}$ in the phosphate buffer $\mathrm{pH} 5.0$ as the supporting electrolyte. The effects of $\mathrm{pH}$ and scan rate on the oxidation peak were studied. The electrochemical behavior of OLV was investigated using cyclic voltammetric $(C V)$, square wave voltammetric (SWV) and differential pulse voltammetric (DPV) techniques. In DPV and SWV, the gold electrode showed a good sensitivity for OLV in a linear range of 0.1-1.5 $\mu \mathrm{M}$ and 0.1-1.3 $\mu \mathrm{M}$ and detection limits of $1.936 \times 10^{-9} \mathrm{M}$ and $4.754 \times 10^{-9} \mathrm{M}$, respectively. A plausible mechanism involving an adsorption controlled oxidation reaction was deduced. The effect of various excipients was also studied and the method was successfully applied for the determination of OLV in human biological samples.
\end{abstract}

\section{Keywords}

Olivetol, electrooxidation, voltammetric techniques, gold electrode

\section{Introduction}

Olivetol (OLV) is one of the naturally occurring alkyl resorcinol and is also known as 5-pentylresorcinol or 5-pentyl-1,3-benzenediol. OLV is benzendiol with an odd numbered carbon chain attached to $5^{\text {th }}$ carbon of the benzene ring, as shown in Scheme 1.

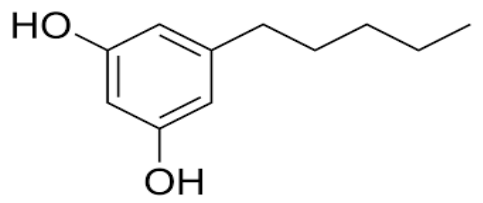

Scheme 1. Structure of Olivetol 
OLV shows an antibiotic behavior [1] and is known to reduce risks of cancer, cardiovascular disease, diabetes and other diseases associated with ageing. OLV acts as an anti-tumor against KB cells that are reported to contain human papilloma viruses closely related to human genital, cervical and oropharyngeal cancers. The cytotoxic potency of OLV is measured, as it produced a $C D_{50}$ (concentration of a compound required for $50 \%$ cytotoxic dose of cell growth) of $105.10 \mu \mathrm{M}$ in 3(4,5-dimethylthiazol-2-yl)-2,5-diphenyl-2H-tetrazolium bromide (MTT) assay and $116.69 \mu \mathrm{M}$ in sulforhodamine B protein (SRB) assay [2]. Several techniques like HPLC [3], gas chromatography (GC) [4] and colorimetry [4,5] have already been used for the determination of alkyl resorcinols, but have proved, however, to be quite expensive and time consuming. Therefore, a sensitive, accurate, cost effective and less time consuming technique is required. Previously, we have studied the electrochemical property of OLV using cyclic voltammetry and differential pulse voltammetry (DPV) with the help of pencil graphite (PGE), glassy carbon (GCE) and carbon paste electrodes (CPE) [6]. In continuation of our previous work on the determination of OLV, another analytical method for the determination of OLV is proposed in the present study. The objective of the study is to find suitable experimental conditions and to investigate the oxidation mechanism of OLV on the gold electrode using square wave voltammetry (SWV), differential pulse voltammetry (DPV) and cyclic voltammetric (CV) techniques. The gold electrode has been chosen because of its stability, wide potential window and fast rate of electron transfer. The method has been proved to be effective even at lower concentrations and also applied for the determination OLV in human fluid samples and in investigation of pharmacokinetics.

\section{Materials and methods}

\section{Reagents and chemicals}

$95 \%$ pure OLV was purchased from Sigma-Aldrich. $1.0 \mathrm{mM}$ stock solution of OLV was prepared using doubly distilled water and stored in the dark and cool place. $0.2 \mathrm{M}$ phosphate buffer stock solutions were prepared within the $\mathrm{pH}$ range of 3.0-10.0 using 98.5\% pure $\mathrm{H}_{3} \mathrm{PO}_{4}, \mathrm{Na}_{2} \mathrm{HPO}_{4}, \mathrm{Na}_{3} \mathrm{PO}_{4}$ and $\mathrm{KH}_{2} \mathrm{PO}_{4}[7,8]$ and double distilled water. Authentic and analytical grade reagents and doubly distilled water were used in preparation of all solutions.

\section{Instrumentation}

CHI630 electrochemical analyzer ( $\mathrm{CH}$ Instruments Inc., USA) was used in the present electrochemical study. The voltammetric experiments were carried out in a conventional threeelectrode system containing the working gold electrode, the platinum wire auxiliary electrode and the $\mathrm{Ag} / \mathrm{AgCl} / \mathrm{KCl}$ reference electrode. $\mathrm{pH}$ measurements were made using an Elico $\mathrm{LI} 120 \mathrm{pH}$ meter (Elico Ltd., India).

\section{Working electrode}

The working electrode used here is the Au disk of $2 \mathrm{~mm}$ in diameter that was placed at the bottom of the three-electrode cell. Since some diminishing of sensitivity of gold electrode due to poisoning of the electrode surface has frequently been observed with successive usage, a pretreatment of the electrode prior to every use is needed to acquire reproducible results. With this aim and prior to each experiment, the Au working electrode was rinsed with double distilled water and polished to get a mirror-like finish using $0.3 \mu \mathrm{m}$ alumina powder on a smooth polishing cloth or polishing pads and rinsed again with double distilled water and dried. Experiments were conducted at room temperature, $25 \pm 0.2^{\circ} \mathrm{C}$. 


\section{Area of the working electrode}

The area of the gold working electrode was determined by variation of the scan rate in cyclic voltammetric experiments in $0.1 \mathrm{M} \mathrm{KCl}$ containing $0.001 \mathrm{M}$ potassium ferricyanide. The effect of the scan rate on the peak current of the $\left(\mathrm{Fe}(\mathrm{CN})_{6}{ }^{3-/ 4-}\right)$ redox reaction is given by the well-known Randles-Sevcik equation [9]:

$$
I_{p a}=0.4463\left(F^{3} / R T\right)^{1 / 2} n^{3 / 2} A D_{0}{ }^{1 / 2} C_{0} U^{1 / 2}
$$

In eq. (1), Ipa is the anodic peak current, $n$ represents the number electrons in the reaction, $v$ is is the scan rate $(\mathrm{V} / \mathrm{s}), A$ is the electrode area $\left(\mathrm{cm}^{2}\right), C_{0}$ is the concentration of the probe molecule in the bulk solution (mol/ $\mathrm{cm}^{3}$ ), while $D_{\mathrm{o}}$ is its diffusion coefficient $\left(7.6 \times 10^{-6} \mathrm{~cm}^{2} \mathrm{~s}^{-1}\right.$ [9]). Using eq. (1) and by knowing the constants, the surface area of gold electrode was calculated to be $0.399 \mathrm{~cm}^{2}$.

\section{Experimental procedure}

Before the beginning of the experiment, all three electrodes were rinsed using double distilled water and then connected to the electrochemical work station. $\mathrm{pH}$ was determined within a $\mathrm{pH}$ range of 3-10. The working parameters for $\mathrm{CV}$ experiments were chosen as: initial potential $-0.4 \mathrm{~V}$; final potential $1.6 \mathrm{~V}$; scan rate $0.1 \mathrm{~V} / \mathrm{s}$; sensitivity $1 \times 10^{-4} \mathrm{~A} / \mathrm{V}$. Effect of the scan rate change was studied at $\mathrm{pH} 5.0$ at the same working parameter values. The working parameters for SWV experiments were chosen as: initial potential $0.4 \mathrm{~V}$; final potential $0.9 \mathrm{~V}$; sensitivity $1 \times 10^{-5} \mathrm{~A} / \mathrm{V}$, while for DPV experiments the working parameters were chosen as: initial potential $0.4 \mathrm{~V}$; final potential $1.4 \mathrm{~V}$ and sensitivity $1 \times 10^{-5} \mathrm{~A} / \mathrm{V}$. All the working parameters were set and reviewed thoroughly before commencing the experiment.

\section{Results and discussion}

\section{Cyclic voltammetric behavior of olivetol}

Cyclic voltammetric behavior of olivetol (OLV) at the gold electrode was studied in $0.2 \mathrm{M}$ phosphate buffer, $\mathrm{pH} 5.0$ solution as the supporting electrolyte. The cyclic voltammograms were measured for the bare gold electrode in either presence (Fig. 1(a)) or absence (Fig. 1(b)) of OLV. Fig. 1(a) shows one anodic peak at $1.041 \mathrm{~V}$. On scanning in the negative direction, a reduction peak at about $0.5 \mathrm{~V}$ was observed as previously [10]. This peak can be ascribed to the reduction of gold oxides and will not be considered further.

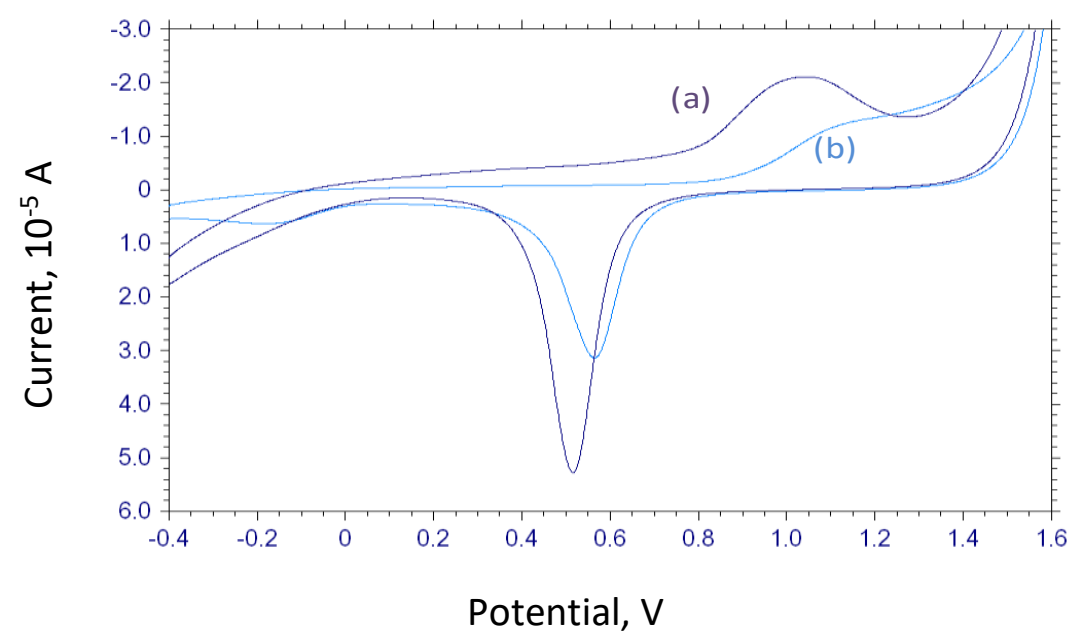

Fig. 1. Cyclic voltammogram of gold electrode in phosphate buffer $\mathrm{pH} 5.0$ solution, recorded at scan rate of $0.1 \mathrm{~V} \mathrm{~s}^{-1}$ in: (a) presence of $0.1 \mathrm{mM} \mathrm{OLV}$; (b) absence of OLV 
In CV experiments, the voltammograms obtained from the first run were always considered. This was due to apparent decrease in oxidative peak current values with successive sweeps which is usually ascribed to adsorption of oxidative products over the electrode surface [11].

\section{Effect of variation of $\mathrm{pH}$}

Effect of $\mathrm{pH}$ change on the electrooxidation of OLV at gold electrode is shown in Fig. 2. It can be observed in Fig. 2(a) that the peak potential values are displaced towards more negative values as the $\mathrm{pH}$ was increased from 3.0 to 10.0 (curves (i-viii)). The highest peak current was observed for $\mathrm{pH}$ 5.0 and so all further experiments were carried at this $\mathrm{pH}$ value. The graph of $E_{\mathrm{pa}}$ versus $\mathrm{pH}$ drawn in Fig. 2(b) showed a linear relationship with a slope of $58 \mathrm{mVpH}^{-1}$ and its linear regression equation is given by:

$$
E_{\mathrm{pa}}=1.299-0.058 \mathrm{pH}\left(r^{2}=0.874\right) \text {. }
$$

The slope value of $58 \mathrm{mV} \mathrm{pH}^{-1}$ is close to the theoretical value of $59 \mathrm{mV} \mathrm{pH}^{-1}[12,13]$, indicating transfer of equal number of protons and electrons involved in the electrochemical reaction.

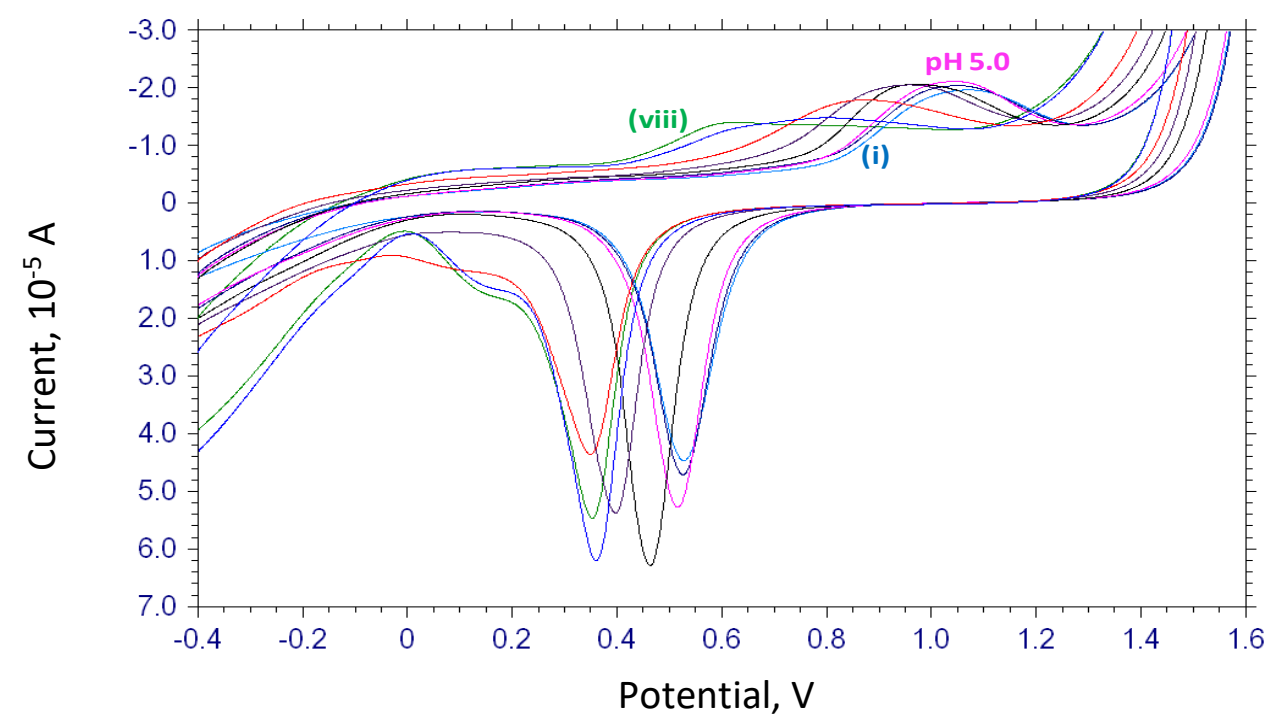

Fig. 2(a). Cyclic voltammograms of gold electrode for $0.1 \mathrm{mM} \mathrm{OLV}$ in the phosphate buffer solution recorded at scan rate of $0.1 \mathrm{Vs}^{-1}$ and $\mathrm{pH}$ 3.0-10.0 (i-viii)

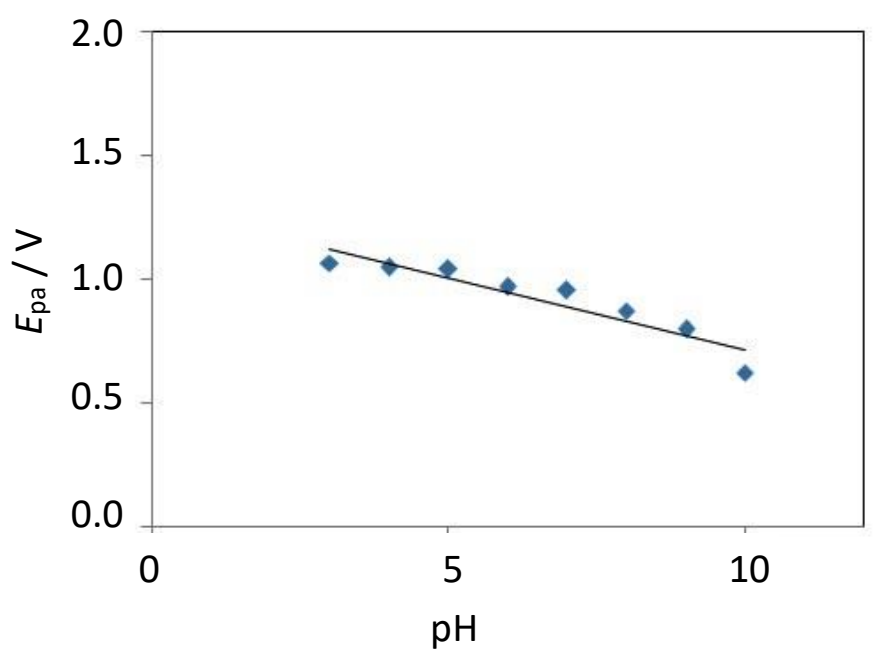

Fig. 2(b). Peak potential $\mathrm{E}_{p a}$ vs. pH dependence 


\section{Influence of scan rate}

Effects of variation of the scan rate over domain of $0.1-0.5 \mathrm{~V} / \mathrm{s}$ on CVs of gold electrode in presence of $1.0 \mathrm{mM} \mathrm{OLV}$ are shown in Fig. 3. The shapes of the voltammograms are obviously dependent on the applied scan rates. When the scan rates were varied in the ascending order (from 0.1-0.5 V/s), there was a steady increase in peak current values, showing a sensitivity of $1.0 \times 10^{-4}$ A/V (Fig. 3(a)).

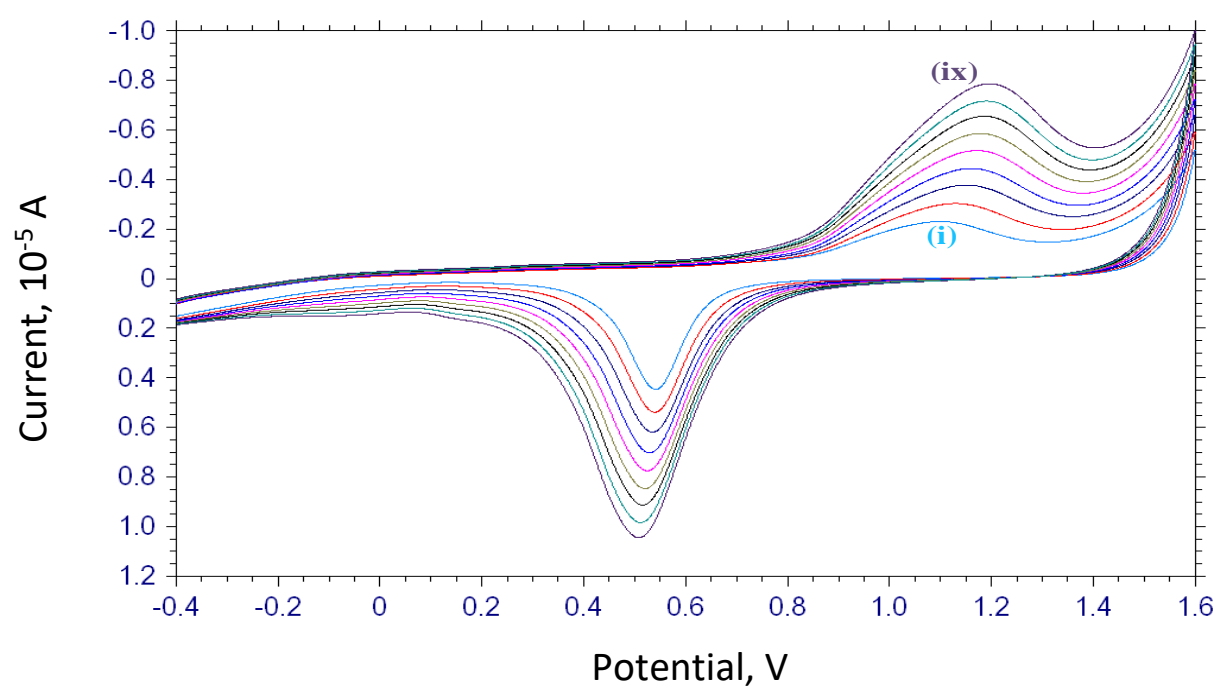

Fig. 3. (a). Cyclic voltammograms of gold electrode in phosphate buffer, $p H 5.0$ solution containing $0.1 \mathrm{mM}$ OLV at different scan rates (0.1-0.5 Vs-1)

The peak current versus scan rate drawn in Fig. 3(b) showed a linear dependence, indicating adsorption regime. The straight line equation is given by:

$$
I_{\mathrm{pa}}=12.73 v+0.858\left(r^{2}=0.999\right) \text {. }
$$

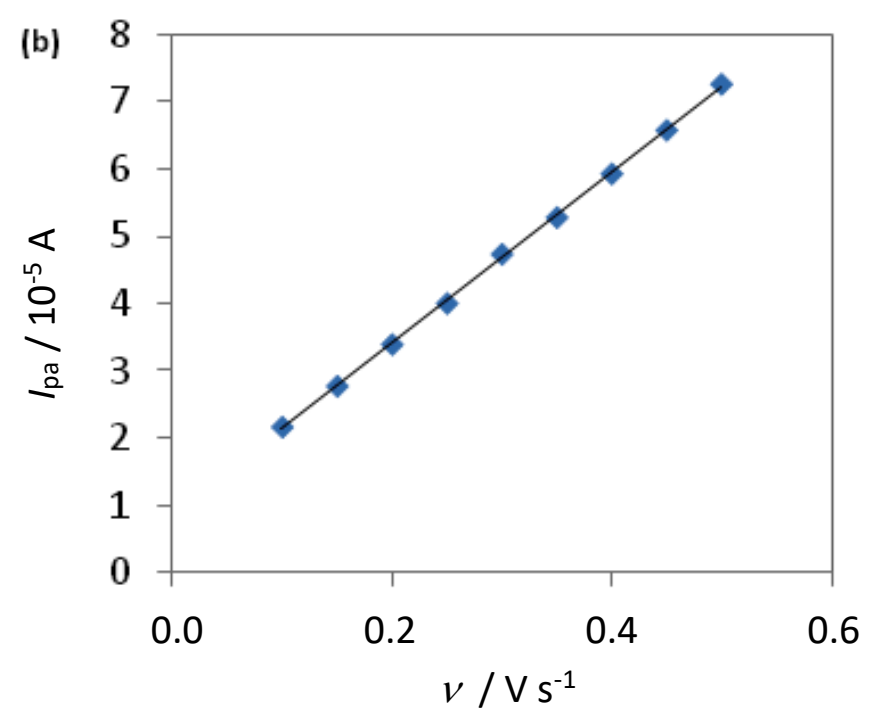

Fig 3(b). Peak current vs. scan rate dependence

From the graph of log of the $I_{\mathrm{pa}} v s$. log of the scan rate given in Fig. 3(c), a straight line was obtained with a slope value of 0.760 . This value is relatively close to 1.0 that is the theoretical value for the adsorption controlled electrode process. The obtained equation is given by:

$\log I_{p a}=0.760 \log v+1.075\left(r^{2}=0.995\right)$. 
(c)

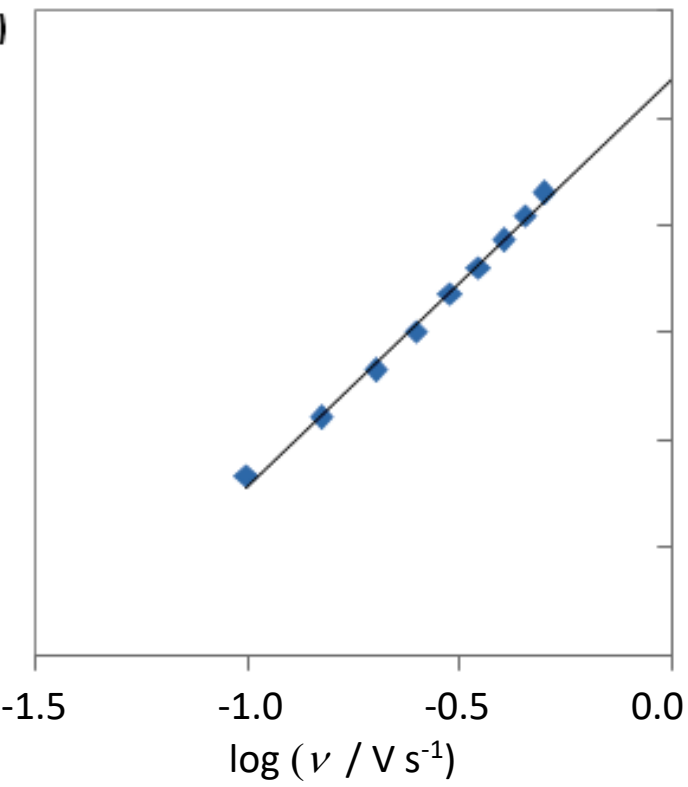

1.2

1.0

0.8

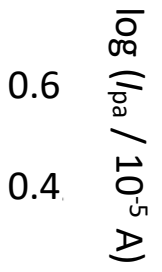

0.2

0.0

Fig. 3(c) log of peak current vs. log of scan rate dependence

Two more graphs showing $E_{\mathrm{pa}} v s . v$ (Fig. 3(d)) and $E_{\mathrm{pa}}$ vs. $\log v$ (Fig. 3(e)) were also drawn, which gave slope values of 0.225 and 0.137 , respectively. With the reference to these graphs, it was observed that with the increase of the scan rate, the oxidation potential shifted towards more positive values. The dependence of $E_{\mathrm{p}}$ on $\log \log v$ is expressed as:

$$
E_{\mathrm{pa}}=0.137 \log v+1.242 \text {. }
$$
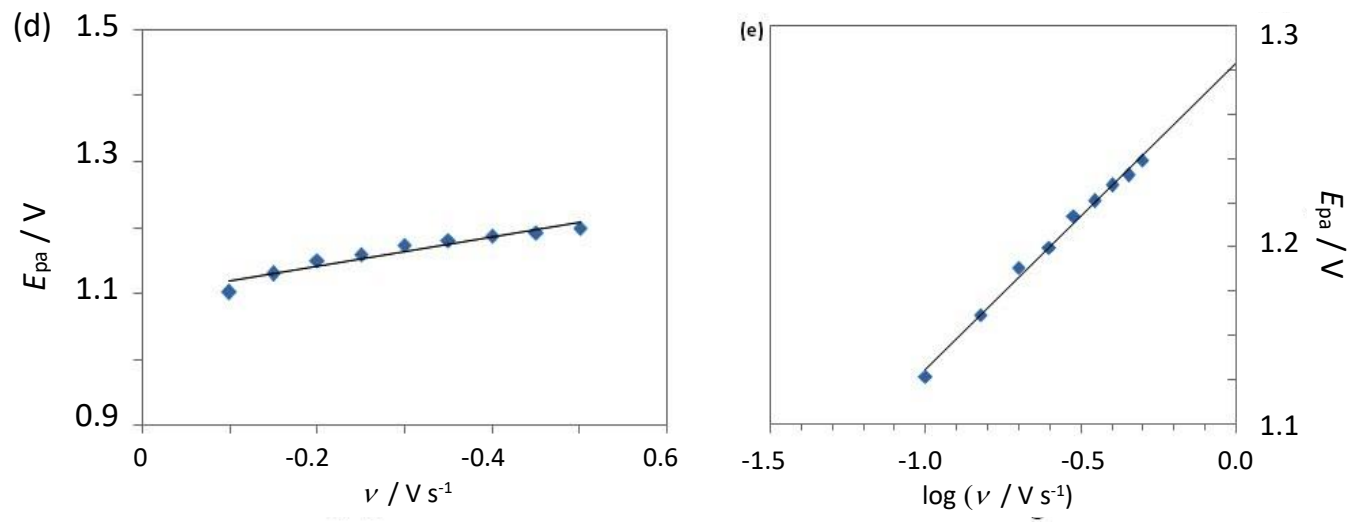

Fig 3(d). Peak potential ( $\left.\mathrm{E}_{p a}\right)$ vs. scan rate (v). (e) Peak potential ( $\left.\mathrm{E}_{p a}\right)$ vs. $\log$ of scan rate (log V).

In order to study the adsorption-controlled irreversible process at the electrode, Laviron [14] suggested the following equation

$$
E_{\mathrm{pa}}=E^{0}+\left(\frac{2.303 R T}{\alpha n F}\right) \log \left(\frac{R T k^{0}}{\alpha n F}\right)+\left(\frac{2.303 R T}{\alpha n F}\right) \log v
$$

In eq. (2), $E^{\circ}$ is the formal redox potential, $R$ is the universal gas constant $\left(8.314 \mathrm{~J} \mathrm{~mol}^{-1} \mathrm{~K}^{-1}\right), \mathrm{T}$ is room temperature $(298.15 \mathrm{~K}), \alpha$ is electron transfer coefficient, $n$ is the number of transferred electrons, $F$ is the Faraday constant $\left(96480 \mathrm{C} \mathrm{mol}^{-1}\right), k^{\circ}$ is the standard rate constant of the surface reaction and $v$ is the scan rate. From the experimental results obtained for the linear graph shown in Fig 3(e), the value of $\alpha \times n$ was determined from its slope ( $m=0.137)$. From the eq. (2) we have: 


$$
m=\frac{2.303 R T}{\alpha n F}
$$

$\alpha$ was calculated from the Bard and Faulkner's [15] equation:

$$
\alpha / \mathrm{mV}=\frac{47.7}{E_{\mathrm{pa}}-E_{\mathrm{pa} / 2}}
$$

In eq. (4), $E_{\mathrm{pa} / 2}$ is the potential measured at the half of the peak current value and hence $\alpha=0.206$. The calculated number of electrons was $2.095 \approx 2$. By extending the line in the graph of $E_{\mathrm{pa}} v s . v$ to the intercept where $v=0$ [16], we get $E^{0}=1.096 \mathrm{~V}$ which was used to calculate the $k^{\circ}$ value using eq. (2):

$$
C=E^{0}+\left(\frac{2.303 R T}{\alpha n F}\right) \log \left(\frac{R T k^{0}}{\alpha n F}\right)
$$

In eq. (5), $C$ is the intercept value obtained from the graph of $E_{\mathrm{pa}} v s$. log $v$. From the above equation, it was possible to determine the value of $k^{\circ}$ as $1.95 \times 10^{2} \mathrm{~s}^{-1}$.

\section{Mechanism}

From the previous results, the number of electrons involved in the reaction was found to be equal to the number of protons and calculated to be equal to 2. Based on the earlier literature [6], a probable mechanism was proposed according to the Scheme 2.<smiles>CCCCc1cc(O)cc(O)c1</smiles>

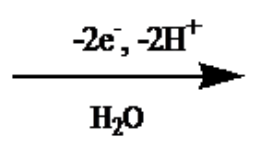<smiles>CCCC(=O)c1cc(O)cc(O)c1</smiles>

Scheme 2. Probable mechanism for the electrooxidation of OLV

\section{Calibration curve and reproducibility}

SWV and DPV voltammograms recorded between $400-850 \mathrm{mV}$ at various concentrations of OLV are presented in Fig. 4.
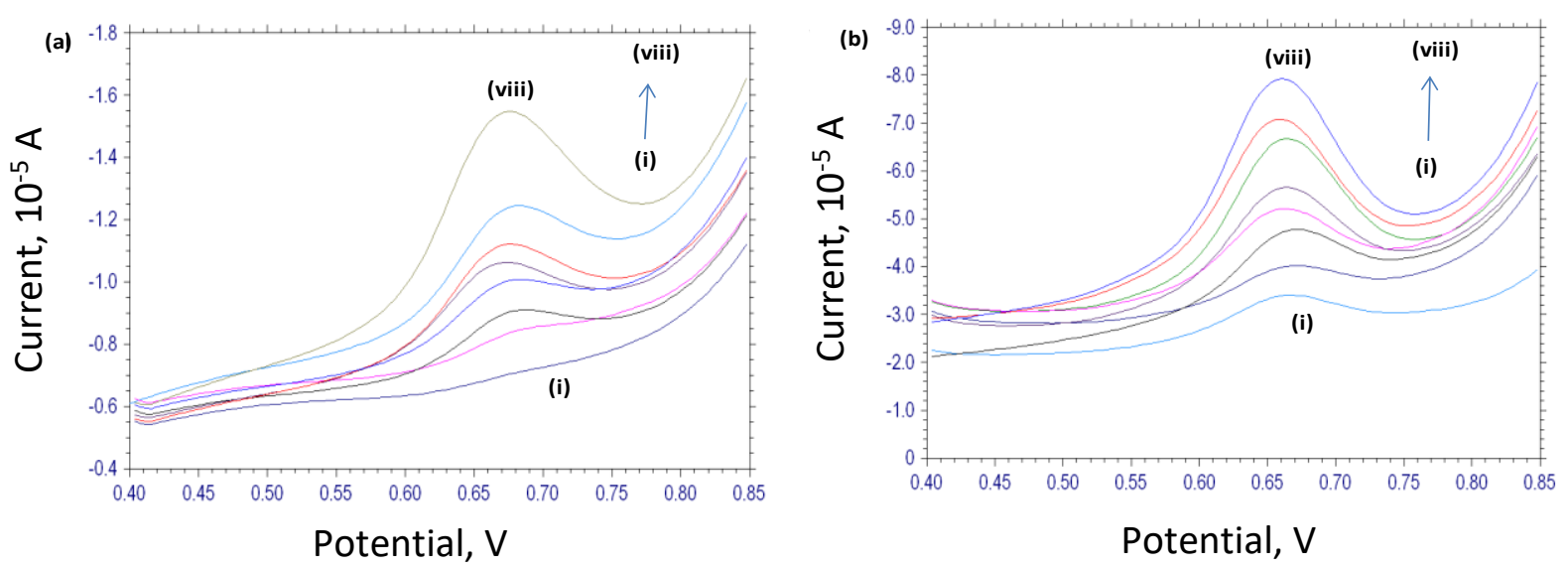

Fig 4. (a) Square wave voltammograms of gold electrode recorded at various concentrations of OLV (i-viii): $0.1,0.3,0.5,0.7,0.9,1.1,1.3,1.5 \mu \mathrm{M}$; (b) Differential pulse voltammograms of gold electrode recorded at various concentrations of OLV (i-viii): 0.1, 0.3, 0.5, 0.7, 1.0, 1.3, 1.5, $1.7 \mu \mathrm{M}$ 
To check the precision of the method, five experiments were carried out on the same day at the same standard conditions which were authenticated by plotting the graphs of peak current values $(/ \mathrm{pa})$ versus concentration of OLV, as is shown in Fig. 5 . The graphs gave linear calibration curves in the concentration range of 0.1-1.3 $\mu \mathrm{M}$ (Fig 5(a)) and 0.1-1.5 $\mu \mathrm{M}$ (Fig 5(b)), respectively. A slight deviation in the calibration curve was observed as the [OLV] was increased, which is due to adsorption behaviour of OLV or its oxidation products on the electrode surface. Characteristics of the calibration plot are given in Table 1. The Limit of Detection (LOD) and the Limit of Quantification (LOQ) values shown in the Table 1 were calculated using the following two equations:

$$
\mathrm{LOD}=3 \mathrm{~s} / \mathrm{m} \text { and } \mathrm{LOQ}=10 \mathrm{~s} / \mathrm{m} \text {. }
$$

In eq. (6), $s$ is standard deviation of the intercept and $m$ is the slope of calibration curve, respectively.
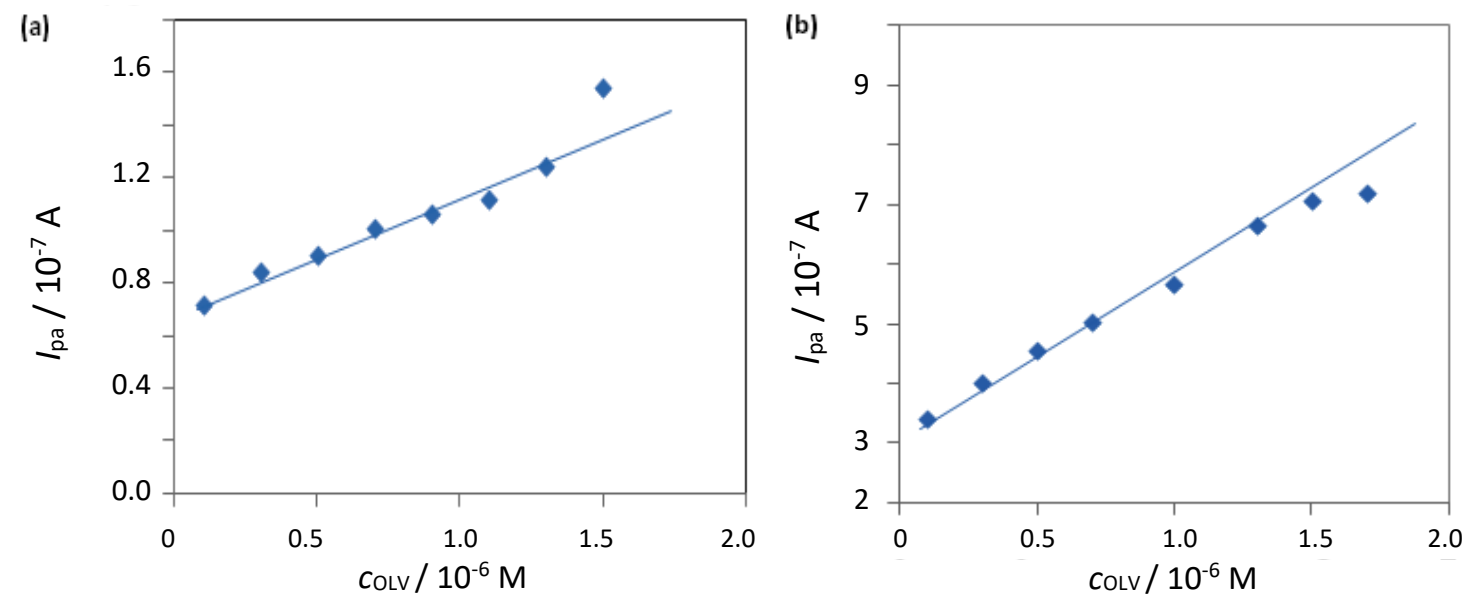

Fig. 5. (a) Calibration plot ( $\mathrm{I}_{p a}$ vs. concentration of OLV) obtained using SWV;

(b) Calibration plot (I $\left.\right|_{p a}$ Vs. concentration of OLV) obtained using DPV

Table 1. Characteristics of OLV calibration plot obtained using SWV and DPV techniques at gold electrode.

\begin{tabular}{ccc} 
& SWV & DPV \\
\hline Linearity, $\mu \mathrm{M}$ & $0.1-1.3$ & $0.1-1.5$ \\
Slope & 0.307 & 0.408 \\
Intercept & 3.105 & 0.701 \\
Correlation coefficient & 0.990 & 0.986 \\
RSD, \% (slope) & 0.569 & 0.856 \\
RSD, \% (intercept) & 0.357 & 0.599 \\
LOD, M & $4.754 \times 10^{-9}$ & $1.936 \times 10^{-9}$ \\
LOQ, M & $1.585 \times 10^{-8}$ & $6.453 \times 10^{-9}$ \\
\hline
\end{tabular}

\section{Effect of excipients}

For probable analytical applications, the effect of certain common excipients used in pharmaceutical preparations on OLV determination has to be been checked. Here, effects of different and potential excipients were studied using the DPV technique and $1.0 \mu \mathrm{M}$ OLV in the presence of $0.1 \mathrm{mM}$ of the chosen excipient. The results are listed in Table 2. The results shown in Table 2 suggest that presence of even hundred-fold excess concentration of an excipient like glucose, citric acid etc., along with certain ions like $\mathrm{Mg}^{2+}, \mathrm{K}^{+}, \mathrm{Cu}^{2+}$ etc., does not interfere much. Thus, the present technique can be used to assay OLV in the presence of various excipients. 
Table 2. Influence of various potential excipients on the DPV response for $1.0 \mu \mathrm{M} \mathrm{OLV}$.

\begin{tabular}{ccc}
\hline Interferents, $\mathbf{0 . 1} \mathbf{~ m M}$ & $\boldsymbol{E}_{\mathrm{pa}} / \mathbf{V}$ & RSD, \% \\
\hline Oxalic acid & 0.7028 & -0.26 \\
Gum acacia & 0.7001 & 0.01 \\
Lactose & 0.6969 & 0.33 \\
Glucose & 0.6938 & 0.64 \\
Starch & 0.6880 & 1.22 \\
Citric acid & 0.6854 & 1.48 \\
Sucrose & 0.6798 & 2.04 \\
$\mathrm{MgSO}_{4}$ & 0.6850 & 1.52 \\
$\mathrm{KCl}_{\mathrm{CuCl}}$ & 0.6806 & 1.96 \\
Sodium citrate & 0.6519 & 4.83 \\
& 0.6850 & 1.52 \\
\hline
\end{tabular}

\section{Effect of surfactants}

It is well known that surfactants affect strongly the electrode processes even if they are present in trace quantities [17]. Surfactants prove to be effective in the electroanalysis of biological compounds and drugs [18]. It was also shown that anionic surfactants could be used to improve the accumulation of some electroactive organic molecules [19]. Cationic and anionic surfactants with varying hydrocarbon chains affect the redox behaviour of electroactive species and bring some irregularities in the voltammograms $[20,21]$. In present study, the DPV technique has been adapted to study the effect of surfactants. Addition of the cationic surfactant, cetyltrimethyl ammonium bromide (CTAB), to the solution did not have any effect on the peak potential value, but the peak current decreased with increase of the concentration of CTAB that is accumulated at the interface. The repulsion between the hydrophobic end of the CTAB and water phase reduces the peak current as the concentration of CTAB is increased [22]. The anionic surfactant, sodium dodecyl sulfate (SDS), influenced the voltammetric behaviour in an opposite way i.e. the peak potentials remained the same but the peak current increased with the increase in concentration of SDS. In both cases only the peak current of OLV showed the surfactant concentration-dependent behaviour.

\section{Detection of OLV in urine samples}

The most striking feature of the method applied to urine samples is that not any prior extraction step is needed. Urine samples from a healthy human volunteer were obtained for the study and the DPV method for the determination of OLV was applied. The urine samples were diluted 100 times using buffer solution before the analysis and not any pre-treatment was made. The recoveries were measured by spiking urine samples with known concentration of drug. The recovery results for three samples are listed in Table 3, together with standard deviations (SD) and relative standard deviations (RSD) values. It is shown in Table 3 that the percentage recovery was in the range of 95-101\%

Table 3: Determination of OLV in urine sample

\begin{tabular}{ccccc}
\hline OLV added, $\boldsymbol{\mu M}$ & OLV found $^{(\mathrm{a})}, \boldsymbol{\mu M}$ & Recovery, $\%$ & SD $\pm \mathrm{RSD}, \%$ & Bias, $\%$ \\
\hline 0.2 & 0.19 & 95.00 & $0.0016 \pm 0.82$ & 0.050 \\
0.6 & 0.61 & 101.66 & $0.0017 \pm 0.27$ & 0.017 \\
0.8 & 0.81 & 101.25 & $0.0019 \pm 0.24$ & -0.012 \\
\hline
\end{tabular}

(a) Average of five determinations 


\section{Application of pharmacokinetics studies}

Clinical applications of pharmacokinetics have resulted in significant improvement in the drug therapy. Pharmacokinetic properties of a particular drug is important to determine the route of administration, dose, onset of action, peak action time, duration of action and frequency of dosing. Pharmacokinetics studies help primarily in enhancing efficacy and decreasing toxicity during a drug therapy. An investigation of effects of various concentrations of drug at the site of action has always been of importance. Direct measurement of drug concentrations at the receptor sites is hardly practicable as the receptor sites might be distributed all over the body. Concentration of drug in blood or plasma, urine, saliva and other easily sampled fluids can, however, be measured. The results suggest that the disposition of OLV was comfortable to a one compartment open model [23]. The rate constant of elimination $\left(k_{\mathrm{e}}\right)$ in a one compartment system is obtained from the plot of concentration of OLV versus time (Fig.6). Using this ' $k_{\mathrm{e}}$ ' value, half life of the drug was calculated which helps in understanding the time interval between the doses and is very important in design of infusion system.

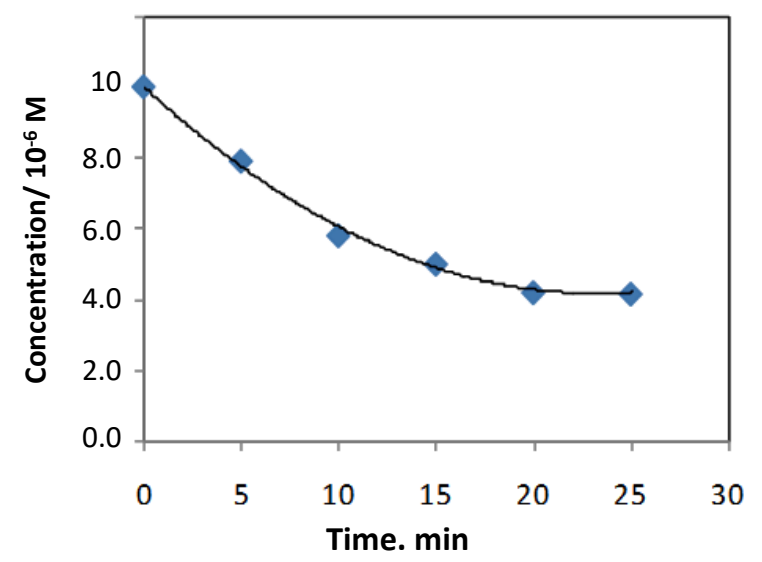

Fig 6. Concentration of OLV vs. time function in spiked urine sample

Table 4 presents the peak current values of $10 \mu \mathrm{M}$ OLV recorded at different times (0-25 minutes), and the values of the elimination rate constant and half-life of the drug. The analytical data obtained suggest that the method is sensitive, reproducible and precise for the determination of OLV.

Table 4. Response of peak current of $10 \mu \mathrm{M}$ OLV in urine sample at different time intervals

\begin{tabular}{ccc}
\hline Time, $\min$ & Peak current, $\mathbf{1 0}^{-\mathbf{7}} \mathbf{A}$ & Concentration of OLV, $\mathbf{1 0}^{-\mathbf{6}} \mathbf{M}$ \\
0 & 9.58 & 10.00 \\
5 & 7.59 & 7.91 \\
10 & 5.59 & 5.82 \\
15 & 4.82 & 5.03 \\
20 & 4.06 & 4.23 \\
25 & 4.02 & 4.19 \\
\hline Elimination rate constant $\left(k_{\mathrm{e}}\right), \mathrm{h}^{-1}$ & 1.12 & \\
\hline Half-life of drug, $\mathrm{h}$ & 0.67 &
\end{tabular}




\section{Detection of OLV in serum samples}

DPV was also applied for the determination of OLV in spiked human serum plasma sample. The recoveries were measured by spiking drug free serum plasma with known amounts of OLV. A quantitative study was made by adding known concentration of standard drug solution in the system of plasma sample which was determined successfully. The results of determination obtained for three plasma samples with recovery and RSD are listed in Table 5.

Table 5: Determination of OLV in human blood serum

\begin{tabular}{ccccc}
\hline Added, $\mu \mathrm{M}$ & Found $^{(\mathrm{a})}, \boldsymbol{\mu M}$ & Recovery, $\%$ & SD \pm RSD, $\%$ & Bias, $\%$ \\
\hline 0.35 & 0.34 & 97.14 & $0.0019 \pm 0.72$ & 0.028 \\
0.55 & 0.56 & 101.18 & $0.0011 \pm 0.32$ & -0.018 \\
0.75 & 0.73 & 97.33 & $0.0021 \pm 0.18$ & 0.026 \\
\hline
\end{tabular}

(a) Average of five determinations

\section{Conclusion}

The voltammetric oxidation of OLV at gold electrode was successfully studied using phosphate buffer, pH 5.0 solution. The oxidation reaction is adsorption controlled and irreversible process. It was found that OLV undergoes a transfer of two electrons and two protons and a plausible mechanism was proposed. A linear relation between peak current and concentration of drug was obtained within a certain range and even $4.7 \mathrm{nM}$ can be used to assay the drug in human urine and blood serum samples. This work has also provided a sensitive and selective method for investigation of the pharmacokinetics of OLV and its possible utilization in the clinical practice.

Acknowledgement: The authors thank University Grants Commission, New Delhi for the award of UGC-BSR faculty fellowship to Dr. S.T.Nandibewoor, and BSR fellowship to Jyoti T.Bagalkoti.

\section{References}

[1] P. Lopez, G. Ferrao, Phytotherapy Research 25 (2011) 271-276

[2] S. H. Baek, Y. O. Kim, J. S. Kwag, K. E. Choi, W. YJung, D. S. Han, Archives of Pharmacal Research 21 (1998) 353-356.

[3] W. J. Mullin, J. P. H. Emery. Journal of Agricultural and Food Chemistry 40 (1992) 21272130.

[4] R. Landberg, A. A. M. Andersson, P. Åman, A. Kamal-Eldin, Food Chemistry 113 (2009) 1363-1369.

[5] W. Mejbaum-Katzenllenbogen, F. Tluscik, A. Kozubek, A. Sikorski, Z .Maresz, Acta Societatis Botanicorum Poloniae 44 (1975) 479-487.

[6] D. G. Patil, V. P. Pattar, S. T. Nandibewoor, Physical Chemistry Communications 4 (2017) 10-23.

[7] J. I. Gowda, S. T. Nandibewoor, Asian Journal of Pharmaceutical Sciences 9 (2014), 42-49.

[8] G. D. Christian, W. C. Purdy, Journal of Electroanalytical Chemistry 3 (1962) 363-367.

[9] B. Rezaei, S. Damiri, Sensors and Actuators B 134 (2008) 324-331.

[10] C. Barus, P. Gros, M. Comtat, S. Daunes-Marion, R. Tarroux, Electrochimica Acta 52 (2007) 7978-7985.

[11] S. S. Kalanur, J. Seetharamappa, G. P. Mamatha, M. D. Hadagali, P. B. Kandagal, International Journal of Electrochemical Science 3 (2008) 756-767.

[12] I. Martins, F.C.Cristiani, S.C. Larissa, A. Francisco, M.C. Letícia, R. Susanne, Talanta 85 (2011) 1-7. 
[13] T. Łuczak, Electrochimica Acta 53 (2008) 5725-5731.

[14] E. Laviron, Journal of Electroanalytical Chemistry 101 (1979) 19-28.

[15] A. J. Bard, L. R. Faulkner, Electrochemical methods; Fundamentals and Applications, Wiley, New York, 2nd ed, (2004), 236

[16] W. Yunhua, J. Xiaobo, H. Shengshui, Bioelectrochemistry 64 (2004) 91-97.

[17] R. Vittal, H. Gomathi, K.-J. Kim, Advances in Colloid and Interface Science 119 (2006) 55-68

[18] B. Hoyer, N. Jensen, Electrochemistry Communications 8 (2006) 323-328

[19] L. Huang, L. Bu, F. Zhao, B. Zeng, Journal of Solid State Electrochemistry 8 (2004) 976-981

[20] United Kingdom Poisoning Information Database (UKPID), ABPI Compdendium of Data Sheets and Summaries of Products, Characteristics Datapharm Publications Ltd. (19961997).

[21] J. Herovsky, J. Kuta, Principles of Polarography; Academic Press: New York, 1966.

[22] J. Abbar, S. T. Nandibewoor, Journal of Critical Reviews in Analytical Chemistry 42 (2012) 272-281

[23] J. I. Gowda, A. T. Buddanavar, S. T. Nandibewoor, Journal of Pharmaceutical Analysis 5 (2015) 231-238.

(C) 2017 by the authors; licensee IAPC, Zagreb, Croatia. This article is an open-access article distributed under the terms and conditions of the Creative Commons Attribution license (http://creativecommons.org/licenses/by/4.0/) 